\title{
Mobility-as-a-Service (MaaS): Comparative analysis of country-specific offerings between Germany and China
}

\author{
Xiao Qin ${ }^{1}$, and Wei Wang ${ }^{2 *}$ \\ 1,2 Research Institute of Highway Ministry of Transport, Beijing, 100088, China.
}

\begin{abstract}
This study focuses on mobility-as-a-service (MaaS) and services. The country-specific differences, which relate to mobility behaviour and supply, as well as the importance of MaaS in Germany and China, are summarised and illustrated by: that the development of MaaS by analysing the current state of mobility offers in Germany and China must be closely compared. With the help of service-dominant logic, self-determination theories and cultural dimensions theory, customer wishes and mobility behaviour are taken into account and discussed in the development of the MaaS, so that one can explore how MaaS responds accordingly and how such offers change. Today's services on the market are presented and summarised, they are public transport, biking, car, ride-sharing, etc. Furthermore, the importance is to be analysed by examining the influence and synergy of the MaaS on the micro, meso and macro levels. The reasons for country-specific differences and own development problems can then be discussed. Finally, the trend towards future development is based on the previous analysis and some recommendations are to be offered for the optimisation of the MaaS offers and their implementation.
\end{abstract}

\section{Introduction}

In the course of the development of new technologies, mobility and its services are becoming increasingly diverse and intelligent. Against this background, some problems and discussions are to be derived, which should be explained in detail in this work. It is about how to define mobility-as-a-service (MaaS) today. What offers does MaaS offer in the specific markets? How do people's mobility behaviour change about the Maas? What is the significance of the MaaS? What are the differences between the different land markets?

This paper will present and analyse MaaS and its offers in Germany and China. Germany is a member of the EU and one of the strongest economic countries in the world. In addition, Germany is at the forefront of the automotive industry, which is considered an advantage for the development of the MaaS. China has been developing rapidly for the last thirty years and has a lot of potential in the market. It is assumed that the cultural differences between the West and the East lead to a different development of the Maas.

In order to answer the above questions, the MaaS offers in Germany and China must be identified and analysed. Finally, a comparison of the MAS is to be made between the two countries in order to understand the development of the MAS in Germany and China.

The work consists of parts. Part I presents the background and objectives of the work. Part II is intended to develop and define the conceptual bases relevant to the subject. In Part III, the explanations in the topic of the creation of mobility-as-a-service are presented by explaining service-dominant logic, the theory of self-determination and the Hofstedes Kulturdimension theory. In Part IV, MaaS is made from four perspectives in terms of theories by the adapted statement, data, information, etc. analysed in order to summarise the continuous development of MaaS in Germany and China. Part V concludes with a brief summary of the overall development of the Maas and a comparison between Germany and China. Part VI is intended to discuss the problems of the MaaS in both countries, and several recommendations are addressed to this end.

\section{Overview of Mobility-as-a-Service}

For five years, mobility services have been developing rapidly in many cities and, instead of the homogeneous products, some mobility service providers have already offered customers heterogeneous services, creating the concept of mobility-as-a-service (MaaS).

The new mobility services such as e-car rental, chauffeur service, car, bike and ride sharing, are combined in a single system, so that users can experience an inclusive mobile service without switching between apps. Mobility services are offered according to customer requirements. In addition, a payment system has been integrated so that users can receive and enjoy a convenient and intelligent mobility service.

The trend of mobility management is gradually evolving towards individual and inclusive provision. MaaS is a single mobility service, accessible according

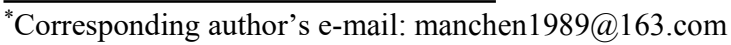


to needs, offered on the Internet or in apps and incorporating the different functions [1]. Therefore, MaaS can be considered as an individual and integrative service offer.

\section{Overview of theories and theories in relation to MaaS}

\subsection{Service Dominant Logic and Changed Customer Requests}

\subsubsection{Good-Dominant-Logic (GDL) and Service-Dominant-Logic (SDL).}

Before Vargo and Lusch established Service Dominant Logic (SDL), the link between goods and services was always explained by the Goods Dominant Logic (GDL). Goods are defined under GDL as material products, i.e. the units of output. GDL expresses itself in such a way that the production and exchange of products can be considered as the core components of business and the economy, because the economic exchange focuses on the units of output embedded in the manufacturing process [2]. In GDL, therefore, customers should only be considered as consumers who accept and purchase the standardised products offered by the manufacturers after an analysis of general customer requirements. From a customer perspective, this is a passive and not an individual service offer.

Resources can be sorted into two types: operating resources and operating resources [3]. Operating resources are static resources that can supply the values by requiring other activities to process such resources first. Operating resources are active resources that contain the ability to act on other resources to create values. The knowledge and competences of the actors are among the operating resources. In SDL, operating resources are considered as core elements.

In terms of operating resources, service can be described as a process in which an entity of itself or can benefit another entity by applying its own knowledge and competences. The service is not considered as intangible goods under SDL, but as a process. Goods, on the other hand, are understood as institutions or measures for the provision of services. The goods and services must be integrated into a service network system in SDL. The producer-consumer view of GDL can therefore be replaced from the perspective of SDL by the concept of market actor, i.e. customers are also considered as actors and play a major role in the value creation process, which can be considered in SDL as co-creation of values. An actor-to-actor network (A2A Network) is thus formed $[4][5][6]$.

\subsubsection{SDL to explain service offerings in response to changing customer requests.}

Based on the SDL declaration, customers are also an actor in value creation, which is why customers can be active under SDL and participate in value creation. The current MaaS services offer the possibility for customers to choose their own mobility service and thus define their mobility behaviour, while the role of users can change flexibly, by being able to offer or enjoy the service in MaaS, for example, a user with their own car driver service can offer and use other services such as bike sharing etc. themselves.

Mobility has traditionally been seen as a typical combination of products and services. On the one hand, companies offer their customers directly the mobility products or the mobility services on the basis of the products, on the other hand, customers can either buy their own means of transport (cars, bicycles, etc.) or choose the mobility services offered by the companies (PSUs). In this situation, customers are passive and there are no or no customers. few individual and service-integrated traces. Compared to the former industrial-dominated company, customers in the current Information and Communication Technologies Society (ICT) can participate relatively directly and more directly in business activities and thus establish close links with other actors [7]. Such companies, as actors, have their dynamic operating resources in MaaS offers, so any actor can benefit from them. Based on the structure of MaaS, the needs of the customer are met. Moreover, the values of the service are not only determined by the service provider, because a process of MaaS service is carried out jointly by many actors. Such particularities are to be found on MaaS, so that the first increases the role of customers in MaaS, that their desires constantly vary according to the needs of mobility services, thus new MaaS offers have emerged and the old mobility offers have changed.

\subsection{The theory of self-determination and mobility}

\subsubsection{Self-determination theory.}

Traditional discussions focused on either environmental factors or individual factors. So and Ryan created the self-determination theory (SDT) so that they can analyze from these two perspectives the causes of personal activities [8]. The SDT refers to the motivation of self-determination of people. Self-determination be both a competence of people and a self-need.

In the SDT the motivations are sorted according to the degree of autonomy: there is the intrinsic motivation, extrinsic motivation and amortization. The intrinsic motivation refers to the fact that one considers oneself because of the intrinsic interest. Lust involved in the activity. The extrinsic motivation describes that one participates in activities because such activities can cause some additional results [9], such as a corresponding reward or reward. Punishment. Amotivation is expressed in such a way t hat you not be motivated to participate in activities.

The SDT stresses that the objectives of meeting psychological needs are to be achieved. Therefore, Deci and Ryan raised three needs: autonomy, competence and belonging [10]. The needs of autonomy relate to the 
regulation of behavior on the self-motivated desire, i.e., one is absolutely excluded from autonomy an $d$ autonomous decisions; one participates in activities out of interest and pleasure. Competence means connecting with the social environment and always feeling interactive in this process in order to be able to represent competences in activities. The needs of competence lead to the pursuit of challenges that are geared to competences. Belonging in this context means that one feels the relationship between oneself and other people, cultures or societies. Membership reflects a tendency to be accepted and recognised by other people and to connect with other people.

\subsubsection{SDT on the declaration on ownership sharing.}

MaaS be a new integrative service offering and is independent of the new means of transport. Mobility services are still provided by cars, trains, taxis, bicycles, etc. completed. Based on the development of ICT and digitisation, companies nowadays are mostly concerned with integrating resources so that they can be optimised in a network or network. Ecosystem can generate profits [11]. This favours some new business models used in mobility services, such as sharing services and collaborative consumption. Bike, car, e-scooter sharing as well as driver service (ride-sharing) are developed on the basis of ICT and digitisation. Whether users participate in new mobility services can usually be summarised in five aspects: economic motives, ecological motives, hedonistic motives, social motives and technological motives [12].

Customers take care of the costs/proceeds of a service offer that MaaS offers can serve to save. According to the ITF study, mobility-related costs have increased significantly since 2020 [13]. In view of the increase in e.g. Fuel, parking, ticket, registration and tax costs should be borne in mind by people, especially car owners, of the impact on their lives.

The ecological motives are sustainability, environmental awareness and the saving of operating resources, most of which relate to non-renewable energies such as oil, natural gas, etc. The ecological view can always be regarded as one of the most important orientations and as a prerequisite in the development of the Maas. In addition, many countries already have environmental laws. Provision shall be made for this to affect conventional means of transport immediately.

The hedonistic motives refer to e.g. Lust, interest, fun etc., which as a feeling come directly from the individual himself. The phenomenon that people are interested in participating in MaaS can be traced back to many different reasons, but they always depend on the individual. The hedonistic motives serve to satisfy the basic needs of autonomy and competence.

Outside the social contact mentioned above, the social motives still contain social responsibility and interaction. To what extent MaaS can contribute to the city and what meanings it can bring, it is first evaluated by the population and then, with the corresponding expectation, the individual decides whether to participate in MaaS. The interaction can stimulate the improvement of the quality of the Maas offer by relaying the feedback received in social contact to relevant actors until problems can be resolved and customers are satisfied with it. Based on social contact in the social media a virtual community that favours the satisfaction of belonging, which is considered to be one of the basic psychological needs, by connecting equals [14].

The technological motives express the ability, security and possibility of the MaaS offer. New technologies can also trigger new product concepts based on modes of transport, mobility service types and business models. This responds to people's mobility behaviour. Customer-friendly feelings such as convenience and flexibility depend on technology. The technological motives as an extrinsic motivation influence the mobility behaviour of the individual. Yet this desire and interest in technologies at MaaS can change.

\subsection{The cultural dimensions by courtyard and cultural differences}

\subsubsection{The cultural dimensions by farm town.}

In the theory of the dimensions of national cultures, culture is collective mental programming that people possess in a social environment. Culture is not an individual symbol, but always a collective phenomenon that refers to group or category-specific people. In order to explain the differences in culture, courtyards derived six dimensions of national culture [15][16]:

Power abstention means the extent to which members expect and accept that power is unevenly distributed. In Hofstadt's study, this dimension focuses on inequality between people. In any society or Organization is inevitable inequality, which is reflected in hierarchies. Power distance is in every social hierarchy.

Collectivism and individualism describe whether interest is subordinated to the interest of the group. In a collectivist society, people take care of the other members and must be loyal to their group for life. Within individual society, each person respects his or her own values and needs, so that through his or her own efforts, man or woman can make a profit. aims to succeed.

The dimension of masculinity femininity reveals to what extent the gender decides which roles men and women play in a society (i.e. gender roles). A society is called masculine when the roles of the sexes are clearly defined emotionally against each other: men are determined to be hard and materially oriented; women, on the other hand, must be more modest, sensitive and value quality of life. A society is called a feminine society when the roles of the sexes overlap emotionally: both women and men should be modest and sensitive and value quality of life.

In the Hofstadt Cultural Dimension Model, the avoidance of insecurity can be defined as the degree to which members of a culture feel threatened by ambiguous or unknown situations and try to avoid this insecurity by establishing new rules and measures [17]. 
The long-term orientation-short-term dimension is defined as follows: long-term orientation stands for the attachment of virtues that are oriented towards future success, persistence and thrift. The short-term orientation stands for the attachment of virtues related to the past and the present, respect for traditions, respect for the'face'and fulfilment of social obligations.

The latest dimension of culture enjoyment-restraint denotes the influences of leisure and work. Enjoyment stands for society, which allows itself the free, enjoyable and fun-related satisfaction of fundamental and natural human desires. Restraint is for society, which controls the satisfaction of needs and manages by means of strict social standards.

Hofstedes Kultur-Dimension-Theory offers the basis and support of the theory so that the differences of culture can be analysed and explained in the current intercultural context.

\subsubsection{Cultural differences in Germany and China.}

Based on the previous survey of courtyards, the dimension index has been established, so it is possible to explain with the help of this index which cultural dimensions a country should belong to. Table 1 provides a summary of the cultural dimensions [18].

Table 1 Cultural dimensions of Germany and China

\begin{tabular}{cc}
\hline Germany & China \\
\hline Small Power Distance & Large Power Distance \\
Individualism & Collectivism \\
Masculinity & Masculinity \\
Large Uncertainty Avoidance & Small Uncertainty Avoidanc \\
Short-term Orientation & Long-term Orientation \\
Restraint & Restraint \\
\hline
\end{tabular}

After examining the cultural dimensions, the cultural dimensions differ in both countries. Based on Hofstedes Cultural Dimension Theory, the development of the MaaS and its importance in Germany and China are influenced, so the development in Germany and China can be quite different.

\section{Country specific differences in MaaS in Germany and China}

MaaS is in a multi-dimensional system, which is why the most important factors should be considered in the in-depth study of the Maas in different countries. Therefore the factors of influence on the company side such as MaaS offers and implementation, customer side such as mobility behaviour and social policy side such as importance and problem are analysed in detail.

\subsection{MaaS in Germany}

According to statistics, cars, public transport and bicycles are most used in Germany today [19]. Even over 51 percent of commuters used cars in one day. Since 2004, the number of people transported by public transport has been increasing significantly in Germany [20]. Based on mobility behaviour, the MaaS offers are currently developing precisely in the areas of cars, public transport and bicycles in Germany. As a result, Bike, Car-Sharing, Chauffeur-Service and Mobile Public Transport offers have emerged in Germany. According to statistics, cars, public transport and bicycles are most used in Germany today [19]. Even over 51 percent of commuters used cars in one day. Since 2004, the number of people transported by public transport has been increasing significantly in Germany [20]. Based on mobility behaviour, the MaaS offers are currently developing precisely in the areas of cars, public transport and bicycles in Germany. As a result, Bike, Car-Sharing, Chauffeur-Service and Mobile Public Transport offers have emerged in Germany.

Bike-sharing is still at the beginning of development in Germany. The infrastructure is currently insufficient for the bicycle in Germany, so that only ten percent of all roads are done by bicycle [21]. This limits the development of bike sharing. These problems are currently being solved gradually in Germany. The report recommended cycling by the Federal Government, because a bicycle cannot generate noise and air pollution. In addition, a bicycle is the optimal means of transport, combining intermodality and multimodality with other means of transport, in order to make the journey of the population more efficient [22]. In most German cities, station-based bike sharing is dominant. It only occurs in metropolises such as Berlin, Munich, Cologne, Frankfurt a. M. etc. as well as some university cities. on. People can change their current mobility behaviour with bike sharing. Accordingly, it can be understood as a rational alternative. The cars, public transport and car sharing were mostly replaced by bike sharing [23]. The market is currently predominantly dominated in Germany by German companies. When using the bike-sharing you do not need a deposit for the bike in Germany. The price of use is between 0.5 euro to 2.4 euro per $30 \mathrm{~min}$.

The MaaS offers of public transport are often used daily in Germany, where people with the help of the apps usually inquire for information. You can also buy a ticket in the smartphone, you usually get a small discount when you pay in the app. The information on means of transport is timely so that you can find out about the latest state of the means of transport. The Bus, Subway, Tram, S-Bahn and Regional Engineering Information are integrated into a platform, so an app can easily address the state of the public transport.

People's attitudes towards the use of travel service intermediaries in Germany tend to be negative. An investigation shows that more than half of the respondents were opposed [24]. So the acceptance of the chauffeur service is quite low in Germany. The reasons may lie. In that most Germans are concerned about their safety, they are therefore happy to accept qualified products. Experts. Taxi drivers must pass the qualification test before they can perform the driving service. The private driver, on the other hand, does not have this qualification. As this is perceived as insecurity, the Germans fear it. As a result, Ride-Sharing developed in Germany mostly by taxi or taxi. Rental. 
Since the first FREE NOW (formerly myTaxi) taxi app is available in Germany, FREE NOW offers a system in which all information can be communicated and coordinated. Users can book, pay and rate a taxi according to their needs in the app. There is little limit to the use of FREE NOW in many European countries. Before that, you had to call if you needed a taxi service. The price plays a big role in taxi service, in the FREE NOW app you can sometimes get a voucher that reduces travel costs. Taxi or Ride-sharing offers also serve to significantly reduce waiting times. The average waiting time of a taxi is approximately five minutes. In the years 2014, FREE NOW became one of the branches of Daimler Mobility Service GmbH, until 2019 the FREE NOW offer was available in over 100 cities and is now part of the Ride-Hailing Joint Venture between BMW and Daimler.

Car-sharing is currently also available in two variants: station-based and station-independent offers. Drivers and car-sharing vehicles of both versions have been increasing ever since 2012. 2017 believed the number of drivers in Germany in 2,11 million (23\%more than 2016) and the number of car-sharing vehicles was at 17.950 (4,4\%more than 2016). Growth is significant for a free float car sharing service. Car sharing is gradually accepted by people in Germany, so that around $11 \%$ of respondents in the 2017 year have used a car sharing app at least once [25]. At the same time 5.000 car-sharing stations have been established in Germany up to 2017. Interestingly, despite fewer vehicles, the free float offers have more users. Since the vehicle is picked up at a station when using the station-based car-sharing and must be returned there, there are some barriers, so you must avoid car-sharing. The Free float Car Sharing vehicle is located where the last customer stopped it. The customer can carry out all steps of the process through apps on his smartphone, i.e. the free float car sharing offers are more comfortable and flexible than others. The station-based car sharing offers are currently available in 677 German cities, while the free float offers are available only in 12 cities [26]. Car-sharing offers are currently being implemented by the different companies. It should be noted that some companies through famous OEM or support or cooperate closely with enterprises with mobility backgrounds. OEM and other conventional mobility companies thus disseminate in the mobility service by means of car-sharing so that they can also gain competitive advantages in the automotive and mobility industries in the future. Car2go and DriveNow are two famous successful examples. Through diffusion in the mobility service, Daimler and BMW can distribute their own products by car-sharing, e.g. electric vehicles (more than 10\% of the fleet) are listed in both offers [27]. People's attitude to car sharing can be considered positive. Although the number of respondents who have used car sharing or are interested in car sharing is still small, it has steadily increased since 2013 [28]. When using car-sharing offers, customers mostly focus on the price, flexibility and ability of the app [29]. Although the potential of car sharing in Germany is currently not fully exploited, its benefits are visible for the traffic situation. If you participate in car-sharing, the amount of cars decreases so that the resources can be used rationally and more places in the city become available [30]. Car-sharing is generally characterised by environmental protection and sustainability, which can have a positive impact on urban development. Furthermore, car sharing is not only seen as a complement to mobility services, but also as an alternative to cars. The Federal Government has acknowledged the importance of car sharing, so the Carsharing Act (CsgG) was passed by the Bundestag in September 2017. On the one hand, car-sharing companies will be subject to the CsgG bspw. In the case of problems with parking and parking fees more supported by government and authority, on the other hand $\mathrm{CsgG}$ also regulates the qualification of providers, business models and the regulation for implementation, so that car sharing in Germany develops under the government directive.

\subsection{MaaS in China}

According to statistics, biking, public transport, car-sharing and ride-sharing are most commonly used in China today [31].

The public transport system in China is different from the German system, because two or more companies run buses and subways in one city. Therefore, some information and resources between both systems cannot be used directly. Each company benefits from its own offer as well as from the mobility service, so the public transport service in China tends to be homogeneous. Almost all offers focus on the information service so that users can find information about the routes, timetables and prices free of charge in the app. Bus and metro are one of the most important resources in China. The situation is even clearer in the metropolises. In China, PPAs are generally supported by the government by being able to receive both the subsidy and a benefit. In addition, almost all bus companies use environmentally friendly vehicle types (electric bus, hybrid bus) that can generate the desire and interest of people, especially young people, so that the public transport service is focused and used by more people [32].

Bike-sharing is currently very popular in China because it plays a major role in the scenario "the last one $\mathrm{Km} "$. The station-independent bike sharing is mostly used in China and the number of users has increased since 2014. At the same time the number of sharing bikes from April 2017 to November 2017 doubled and was at 23 million. In November 2017, Bike Sharing users in China cheated approximately 400 million. In China, free float offers are dominant. Bike sharing has been offered in many cities, which is why it can already be considered accepted in China. Almost all bike sharing offers have been established by start-ups, but due to the great competition many offers are declining. The price is so cheap in China that more and more people use bike sharing. The price is approximately 0.1 to 0.2 Euro per half hour, this is much cheaper than bus and metro. A study describes that users in China focus on experience of travel, costs and flexibility [33]. 
The taxi industry is changing step by step with the development of digitisation in China. To benefit from this, many taxi companies engage in ride-sharing either by developing their own offers or by cooperating with ride-sharing companies to integrate their resources into ride-sharing companies. During the period 2014 to 2017, several respondents used the Ride-Sharing offers. This phenomenon may be due to the fact that the Ride-sharing offers make the journeys comfortable, flexible and efficient. Since the resources of the taxis could not be distributed rationally in metropolis before the advent of the Ride-Sharing offers, and the demand for MIV (motorised individual transport) was increasing, the users were not satisfied with the experience. Long waiting time made mobility ineffective. This benefits from the rational allocation of Ride Sharing resources, which is why the offers were accepted very quickly in China. Ride-sharing offers can only partially fill the gaps in mobility demand at the moment by establishing some Ride-Sharing start-ups in China in recent years that develop their market-adapted offers in China. In China, Ride-Sharing has contributed to improving the transport environment and structure by reducing the average number of cars driven 2015 per day by 283.368 cars, while at the same time half of Ride-Sharing users found that this facilitated congestion [34]. Thus, the resources of the roads were freed up more. The dominant offers have been established by start-ups and taxi/rental companies. DiDi Chuxing has most service options and contains most available resources. Users in China are more concerned about efficiency, flexibility and costs when using ride sharing. Above all, mobility needs are to be met, which is why Ride-Sharing is currently seen as a solution to the lack of MIV.

Since the Chinese government has adopted Internet Plus, the mobility industry has also benefited from it. Each company shall address the digitisation of its offers as soon as possible, the rental companies. Car sharing is also becoming more popular in China, which is why the large car rental companies have merged their services with the new car sharing offers. In addition, some OEMs also participate in car sharing. In China, most car-sharing offers take the station-based form by companies using their own stations or co-operated parking spaces. The station-based offers can offer several available vehicles and can be easily distributed compared to free-float car sharing in other cities. Most of the offers were made by OEM or Car-sharing is also a channel for the diffusion of conventional OEMs and mobility companies. Another reason should be borne in mind: because many companies carry out their offers with electric vehicles, 95 percent of the electric car fleet. Therefore, station-based car sharing is dominant in China. An investigation shows that most people in China are interested in car sharing. In addition, around $87 \%$ of respondents will continue to use car sharing. Car sharing users focus in China parking, security, number of vehicles and costs [35].

\subsection{Importance of MaaS in Germany and China}

MaaS can come into our lives as a new concept in the field of mobility services, so that its importance can be found in the micro, meso and macro levels.

The micro-level refers to the MaaS actor level, i.e. to transport providers, MaaS operators and users. MaaS can undoubtedly enhance the ability to meet people's demand for mobility by creating many mobility concepts appropriate to the digital age. In addition, customers have several choice options in the mobility service. In Germany, the demand for mobility services may not be as high in the future as in China, so people can become more aware of quality and individualisation. Focus personalization. If necessary, MaaS can weigh up the relationship between costs and the quality of mobility services. give an answer. The value-sharing of individuals in Germany is likely to change significantly in the future, since Uber and Airbnb have been successful worldwide through the Share concept, the part-based collaborative consumption model may be a trend in the future.

The Meso level covers the entire mobility industry. The diversification of a sector represents the overall capacity of a sector in the world. MaaS serves to integrate the different resources, i.e. other industries can participate in MaaS. ICT, financial companies, etc. can play an important role in the development of the MaaS. At the same time, diversification for the mobility service itself optimises, if necessary. the availability and structure so that the city and the authority can find a rational orientation. In Germany, the level of technology and industries is relatively high compared to other countries and MaaS may be located. in many industries. Therefore, several values can be created with the help of efficient coordination and deep collaboration between the actors in Germany. MaaS makes the mobility service an open innovation-oriented business.

The macro-level covers the entire Maas ecosystem. MaaS strengthens the entire capacity for mobility in the city. It aims to promote sustainability, environmental protection and resource allocation. If MaaS develops further in a city, more manpower will probably be needed in the future. Through the development of the MaaS, the city can develop into a smart city. In addition, the mobility behaviour of the population of MaaS can influence. The provisions and measures of the MaaS can influence the authority, i.e. the population of the city can deal directly with the transformation of the mobility system.

The meaning of MaaS plays a similar role in China as in Germany. The difference is that the structure of mobility will not vary soon, particularly in metropolitan areas, because each sector focuses on the development of its own supply and each regulates its own affairs in its own way. Close cooperation between different sectors in China is therefore somewhat neglected. However, the diversification of homogeneous mobility services increases the choice for customers, thus meeting demand. Moreover, after being checked and checked, you can use your own car to practice private commercial Ride-Sharing in China. Therefore private property is 
linked as a resource to the public, which facilitates the lack of mobility resources.

\section{Comparison of results between Germany and China}

The development of the MaaS and its offers can be considered positive in Germany and China, because the MaaS offers are being established in more and more cities and their service options are becoming more and more varied. However, MaaS and its offer in Germany and China embody the different characteristics. An overview of MaaS is shown in Table 2.

In the future, MaaS and MaaS offers will develop in Germany and China without technical barriers, i.e. companies should focus on disseminating their MaaS offers, especially in Germany. The current offer of mobility in China does not meet the needs. In addition, the population must be confronted with policy constraints and environmental pressures. It is precisely these problems that can partially solve MaaS offers, which is why MaaS was immediately accepted in China. However, the transport situation in Germany is comparatively better than in China, which is why people lack the motivation to participate in MaaS. In addition, users in China can benefit from competition between providers, so that costs are cheaper than conventional mobility services, while costs are scarcely reduced when people in Germany use MaaS offers. The Germans are relatively careful, so they tend to the developed products and services.

\section{Discussion of MaaS in Germany and China}

Although MaaS has taken a major step forward in Germany and China, it is also necessary to confront some problems at the same time.
In Germany, the mobility gaps are not as large as in China, so the MaaS offers can focus more on improving the quality of mobility experience and the incentive to pleasure. Bike sharing offers can first reduce the complexity of use by using the intelligent closing cycle system, i.e. users can connect a bicycle in apps with the help of code scanning and then simply start cycling. After use, the costs are automatically booked from your account. Ride-sharing offers are limited in Germany, but rental or taxi companies can diversify vehicle types and services to meet different needs and to demonstrate environmental awareness. Car-sharing companies should rationally distribute and plan their vehicles and stations through the $\mathrm{CsgG}$ in the city and facilitate the use of their offers.

In China, in view of the major deficiencies in mobility demand, MaaS must pay attention to how to optimise existing transport resources in the city. Furthermore, MaaS companies should cooperate with each other so that bus and metro systems can be integrated into MaaS, although this is a difficult task. Bike sharing should focus more on the parking problem by setting up, where appropriate, a system of reliability so that the undisciplined users can be restricted to the next use. Ride-sharing is currently a preferred mobility service in China, which is why the monopoly of a company becomes dangerous for the initial Ride-Sharing service. This requires not only competition from other companies but also government action.

As a new mobility concept adapted to the Internet age, MaaS has many meanings, which is why people expect rational MaaS offers. Although the development of the MaaS and its offerings will have to face permanent barriers in Germany and China in the future, it cannot be doubted that MaaS is currently providing an opportunity in the mobility sector to release the pressure on resources and the environment and to facilitate our mobility behaviour.

Table 2 MaaS in Germany and China

\begin{tabular}{|c|c|c|}
\hline MaaS Service & Germany & China \\
\hline $\begin{array}{l}\text { Public } \\
\text { Transport }\end{array}$ & $\begin{array}{l}\text { 1. You can order and pay for the ticket in } \\
\text { apps. } \\
\text { 2. Public transport is used by most users, the } \\
\text { level of network coverage is good. } \\
\text { 3. The functions are sufficient in apps, the } \\
\text { service is in basic service. }\end{array}$ & $\begin{array}{l}\text { 1. Most apps can only provide information service. } \\
\text { 2. DR-Service (Demand Responsive) is available in } \\
\text { some cities by ordering on the Internet or in apps. } \\
\text { 3. The number of users is large, the subway is the most } \\
\text { popular. }\end{array}$ \\
\hline Bike-Sharing & $\begin{array}{l}\text { 1. The station-based offer is dominant. } \\
\text { 2. The number of users is increasing every } \\
\text { year, the number of users is still small. } \\
\text { 3. The offers are mostly in metropolis. } \\
\text { 4. Most of the offers have been established } \\
\text { by the German companies. } \\
\text { 5. The cycling paths and adjustment are the } \\
\text { main factors influencing the participation of } \\
\text { users. }\end{array}$ & $\begin{array}{l}\text { 1. The station independent offer is dominant. } \\
\text { 2. The number of users increases significantly each year. } \\
\text { 3. The offers are located } 2016 \text { in } 263 \text { cities. } \\
\text { 4. Offers have been established by Chinese startups. } \\
\text { 5. The flexibility is most taken into account by the users, } \\
\text { flexible connection between stop and home, free } \\
\text { parking. } \\
\text { 6. Most offers require bail. }\end{array}$ \\
\hline
\end{tabular}

6. Offers do not require a deposit. 


\begin{tabular}{|c|c|c|}
\hline Ride-Sharing & $\begin{array}{l}\text { 1. People's acceptance of Ride-Sharing is } \\
\text { low. } \\
\text { 2. Ride-sharing service is strictly limited by } \\
\text { law. } \\
\text { 3. Driver service is provided by taxi and } \\
\text { rental companies, e-taxi is preferred. } \\
\text { 4. The offers are mostly supported by } \\
\text { mobility companies. } \\
\text { 5. Costs are important to customers. } \\
\text { 6. The vouchers are sometimes offered in an } \\
\text { app. }\end{array}$ & $\begin{array}{l}\text { 1. The acceptance of people to ride-sharing is quite high. } \\
\text { 2. Ride-sharing is controlled by government, but private } \\
\text { drivers can exercise it. } \\
\text { 3. Driver service is available in many versions, and is } \\
\text { currently most commonly used in Ride-Sharing. } \\
\text { 4. Most of the offers have been established by local } \\
\text { startups and taxi/rental companies. } \\
\text { 5. Flexibility, transparency, experience and method of } \\
\text { payment are the most important considerations of users. } \\
6 \text {. The coupons and discounts can sometimes be } \\
\text { obtained in an app. }\end{array}$ \\
\hline Car-Sharing & $\begin{array}{l}\text { 1. The two versions of the car-Sahring are } \\
\text { equally important. } \\
\text { 2. The Free-float User Anzhal is significantly } \\
\text { more than station-based. } \\
\text { 3. Most offers are closely linked to OEM and } \\
\text { some have been established directly by } \\
\text { OEM. } \\
\text { 4. Few people are currently interested in car } \\
\text { sharing. } \\
\text { 5. CsgG favours car-sharing industry. }\end{array}$ & $\begin{array}{l}\text { 1. The station-based offers are dominant because of the } \\
\text { type of fleet. } \\
\text { 2. The proportion of station-based users is higher than } \\
\text { station-independent. } \\
\text { 3. Most station-based offers accept that pick-up and } \\
\text { return are conducted in different stations. } \\
\text { 4. Most offers are supported by OEM and rental } \\
\text { companies or established. } \\
\text { 5. Most people want to carshare. }\end{array}$ \\
\hline
\end{tabular}

\section{References}

1. MaaS Alliance (2018), What is MaaS? https://maas-alliance.eu/homepage/what-is-maas/

2. Vargo, S. L., Lusch, R. F. (2008): From goods to service(s): Divergences and convergences of logics. Industrial Marketing Management, Vol. 37, No. 3: 254-259.

3. Lusch, R. F., Vargo, S. L. (2014) Service-Dominant Logic - Premises, Perspectives, Possibilities. Cambridge University Press, Cambridge.

4. Lusch, R. F., Nambisan, S. (2015) SERVICE INNOVATION: A SERVICE-DOMINANT LOGIC PERSPECTIVE. MIS Quarterly, Vol. 39, No. 1: 155-176.

5. Li, L., Jian, Z., Zhang, L. (2013) An Analysis of Causes and Core Viewpoints of Service Dominant Logic and Future Prospects. Foreign Economics and Management, Vol. 35, No. 4: 2-12.

6. Vargo, S. L., Lusch, R. F. (2016) Institutions and axioms: an extension and update of service-dominant logic. Journal of the Academy of Marketing Science, Vol. 44, No. 1: 5-23.

7. Ambrosino, G., Nelson, J. D., Boero, M., Pettinelli, I. (2016) Enabling intermodal urban transport through complementary services: From Flexible Mobility Services to the Shared Use Mobility Agency: Workshop 4. Developing intermodal transport systems. Research in Transportation Economics, Vol. 59: 179-184.

8. Deci, E. L., Ryan, R. M. (1985) The general causality orientations scale: Self-determination in personality. Journal of Research in Personalit, Vol. 19, No. 3: 109-134.

9. Ryan, R. M., Deci, E. L. (2000) Intrinsic and Extrinsic Motivations: Classic Definitions and New Directions. Contemporary Educational Psychology, Vol. 25, No. 1: 54-67.
10. Ryan, R. M., Deci, E. L. (2004) Overview of Self-Determination Theory: An Organismic Dialectical Perspecktive In: E. L. Deci und R. M. Ryan (Eds.): Handbook of Self-Determination Research, University of Rochester Press, Rochester \& Suffolk. pp. 3-33.

11. Kamargianni, M., Li, W., Matyas, M., Schäfer, A. (2016) A critical review of new mobility services for urban transport. Transportation Research Procedia, Vol. 14: 3294-3303.

12. Lichter, D. (2017) Teilnahmemotive und Notwendigkeit von Corporate-Private-Public-Kooperationen in der Share Economy, Forschungsbericht Nr. 13. von Rolf Weiber, Trier.

13. Möhlmann, M. (2015) Collaborative consumption: determinants of satisfaction and the likelihood of using a sharing economy option again. Journal of Consumer Behaviour, Vol. 14, No. 3: 193-207.

14. Botsman, R., Rogers, R. (2010) What's mine is yours - the rise of collaborative consumption, Harper Collins, New York.

15. Hofstede, G., Hofstede, G. J. (2011) Lokales Denken, globales Handeln. Deutscher Taschenbuch Verlag, Munich.

16. Hofstede, G. (2011) Dimensionalizing Cultures: The Hofstede Model in Context, Online Readings Psychology and Culture, 2(1). https://doi.org/10.9707/2307-0919.1014

17. Hofstede, G. (1991) Cultures and Organizations software of the mind. McGraw Hill, New York.

18. Zhou, Z., Jin, X., Fang, Y., Vogel, D. (2015) Toward a theory of perceived benefits, affective commitment, and continuance intention in social virtual worlds: cultural values (indulgence and individualism) matter. European Journal of Information Systems, Vol. 24, No. 3: 247-261.

19. Statista (2018) Wie oft benutzen Sie die folgenden Verkehrsmittel in Ihrer Umgebung? 
https://de.statista.com/statistik/daten/studie/2267/um frage/alternative-verkehrsmittel-zum-eigenen-auto/

20. Statistisches Bundesamt (2017) Anzahl der beförderten Personen mit Bussen und Bahnen im Liniennahverkehr in Deutschland in den Jahren 2004 bis 2017. https://de.statista.com/statistik/daten/studie/12556/u mfrage/befoerderte-personen-im-liniennahverkehr-in -deutschland/

21. BMVI (2017) Fahrradverkehr. http://www.bmvi.de/DE/Themen/Mobilitaet/Strasse/ Fahrradverkehr/fahrradverkehr.html

22. BMVBS (2012) Nationaler Radverkehrsplan 2020. RitterSlagman Werbeagentur, Hamburg \& Berlin.

23. Statista (2017) Welche Alternative ersetzen Sie in der Regel durch Leihrräder? https:/de.statista.com/statistik/daten/studie/671026/ umfrage/leihfahrraeder-als-alternative-zu-anderen-v erkehrsmitteln-in-deutschland/

24. YouGov (2017) Es gibt Fahrdienstvermittler, die Fahrer per App auf dem Smartphone vermitteln. Dadurch werden normale Autofahrer zu Chauffeuren. Würden Sie einen solchen Dienst nutzen? https://de.statista.com/statistik/daten/studie/708661/ umfrage/nutzung-von-fahrdienstvermittlern-in-deuts chland/

25. Statista (2017) Anteil der Personen in Deutschland, der schon einmal eine Carsharing-App benutzt hat im Jahr 2017 https:/de.statista.com/statistik/daten/studie/718943/ umfrage/nutzungserfahrung-von-carsharing-apps-indeutschland/

26. BCS (2018) Datenblatt CarSharing in Deutschland https://carsharing.de/sites/default/files/uploads/daten blatt_carsharing_in_deutschland_stand_01.01.2018 final.pdf

27. InnoZ (2017) Anteil der Elektrofahrzeuge in Flotten von ausgewählten Carsharing-Anbietern in
Deutschland.

https:/de.statista.com/statistik/daten/studie/789578/ umfrage/anteil-der-elektrofahrzeuge-in-flotten-von-c arsharing-anbietern-in-deutschland/

28. IfD Allensbach (2017) Anzahl der Personen in Deutschland, die Carsharing nutzen oder sich dafür interessieren, in den Jahren 2013 und 2017. https:/de.statista.com/statistik/daten/studie/257867/ umfrage/carsharing--interesse-und-nutzung-in-deuts chland/

29. Horizont (2018) Umfrage zu wichtigen Eigenschaften beim Carsharing in Deutschland im Jahr 2018. https://de.statista.com/statistik/daten/studie/811665/ umfrage/umfrage-zu-wichtigen-eigenschaften-beimcarsharing-in-deutschland/

30. iResearch (2016) China E-hailing service user report 2015 http://www.iresearch.com.cn/Detail/report?id=2502 \&isfree $=0$

31. Tsang, R., Boutot, P-H., Cai, D. (2018) China's Mobility Industry Picks Up Speed. http://www.bain.com/publications/articles/chinas-m obility-industry-picks-up-speed.aspx

32. amap.com (2018) 2017 China Public Transport Big Data Analysis in Major Cities. http://report.amap.com/download_city.do

33. iResearch (2017) China Bikesharing market report 2017.

http://www.iresearch.com.cn/Detail/report?id=2961 \&isfree $=0$

34. Bundesverband CarSharing

Carsharingjahresbericht 2015-2016. http:/carsharing.info/sites/default/files/uploads/bcs jahresbericht_20152016_mail.pdf

35. iiMedia Research (2017) 2016 China Carsharing market report http://www.iimedia.cn/51450.html 